\title{
Topical corticosteroid misuse: observational study to evaluate pattern of abuse and adverse drug reactions
}

\author{
Bhawna Saini $^{1 *}$, Yatendar Chahar ${ }^{2}$, Yogesh Kumar Goyal ${ }^{3}$, \\ Mohit Kumar ${ }^{4}$, Arkapal Bandyopadhyay ${ }^{1}$
}

\begin{abstract}
${ }^{1}$ Department of Pharmacology, ${ }^{4}$ Department of Anaesthesia, AIIMS, Rishikesh, Uttarakhand, India

${ }^{2}$ Department of Dermatology,

${ }^{3}$ Department of Pharmacology,

S. N. Medical College, Agra,

Uttar Pradesh, India
\end{abstract}

Received: 19 June 2019

Accepted: 31 July 2019

*Correspondence to:

Dr. Bhawna Saini,

Email: bhanu.gsvm@gmail.com

Copyright: (C) the author(s), publisher and licensee Medip Academy. This is an openaccess article distributed under the terms of the Creative Commons Attribution NonCommercial License, which permits unrestricted noncommercial use, distribution, and reproduction in any medium, provided the original work is properly cited.

\begin{abstract}
Background: Topical corticosteroids (TC) have a reputation as anti-acne, antiblemish effects and popularly used as fairness creams. In India, there has been a rise in misuse of TC in last10 years. The present study was conducted to analyse the magnitude of adverse effects of topical corticosteroids abuse in dermatology outpatient department of a tertiary care hospital.

Methods: A retrospective observational study was conducted on patients after categorizing them as a TC misuser by dermatologists. The socio-demographic data, chief complaints, details of drugs misuse and adverse drug reaction outcome was collected.

Results: A total of 1240 patients was screened, out of which 80 patients misused TC without dermatologist prescription for their skin disease. TC was mainly misused by teenagers $(43.8 \%)$. Misuse of topical corticosteroids was more common among females $(76.3 \%)$. Betamethasone valerate $(72.5 \%)$ was most common TC misused. Most common source of advice of TC misuse was friends $(37.5 \%)$. Most common purpose of TC misuse was acne $(55 \%)$ followed by cosmetic purposes $(21.3 \%)$. The most common morphological varieties of adverse drug reactions were burning and itching sensation $(53 \%)$ followed by increase severity of acne (44\%).

Conclusions: TC misuse was more common in teenage females. Most common adverse effect reported is burning and itch sensation followed by increase severity of acne. The study data indicates a significance of problem and requirement of urgent measures to control TC misuse.
\end{abstract}

Keywords: Topical corticosteroids, Acne, Adverse drug reactions, Self medication

\section{INTRODUCTION}

Topical corticosteroids (TC) are hydrocortisonederivative compounds with potential anti-inflammatory activity. The quick amelioration of signs and symptoms of many skin disorders by the application of topical corticosteroids attracts the attention of several people who start using them without guidance of a dermatologist practitioner. $^{1}$

TC misuse is double edged sword. Initially use of TC shows vasoconstrictive and anti-inflammatory effects that result in clearance of the primary dermatosis but after prolonged application, patients develop rashes and sudden stopping the drug lead to recurrence of rashes i.e. rebound phenomenon. ${ }^{2}$ So, to prevent this effect, the patient resumes the use of topical corticosteroids products. In the end, skin is rendered extremely vulnerable to bacterial, viral and fungal infections. Indiscriminate use of topical corticosteroids may lead to rapid resistance of current antifungal drugs thus making treatment of fungal infections a therapeutic nightmare for dermatologists. 3,4 
Vast sections of the Indian society have willingly or unknowingly become victims to the craze of beautification leading to a virtual epidemic of monomorphic acne, steroid atrophy, steroid rosacea, telangiectasia, perioral dermatitis and striae like conditions. 5

A report "Topical steroid misuse menace" submitted in 2006 to Indian Association of Dermatologists, Venereologists and Leprologists (IADVL) turned out to be a mile stone which has drawn attention of dermatologist towards the major concern of misuse of topical corticosteroids in India. As per the information available on the Central Drugs Standard Control Organization (CDSCO) website regarding approved dermatological indications of topical corticosteroids, its off-label use seems to be a common clinical practice in India. ${ }^{4}$ Online academic forum of IADVL revealed the rapidly rising incidence of topical corticosteroids misuse on the face all over India. ${ }^{2}$

In India, according to the intercontinental marketing services (IMS) health agency, the annual sales figure of topical corticosteroids for 2013 at the end of December stood at 1400 crores rupees, showing an annual growth of $16 \%$. The sale accounts for $82 \%$ of the topical dermatological product sale in the India, a clear reflection of the popularity of topical steroids. ${ }^{2}$ Approximately, $\$ 138$ million worth of topical corticosteroids are sold in India annually over the counter without prescription support and on the advice of laymen. ${ }^{5}$ This may only be the tip of the iceberg which reveals that the actual sales figure might be much higher. Indiscriminate and prolonged use of topical corticosteroids leads to deterioration of patient condition as well as economic burden on society.

TC misuse leads to side effects which depend on potency of steroid, duration of use, volume of the product applied, site of application and age of the patient. Cutaneous side effects caused by TC include skin atrophy, stretch marks (striae), easy bruising and tearing of the skin, enlarged blood vessels (telangiectasia), perioral dermatitis, hypopigmentation, acneiform eruptions, hypertrichosis, aggravation of cutaneous infections, rosacea-like dermatitis, delayed wound healing, alterations in skin elasticity and mechanical properties. Systemic side effects are usually seen after long exposure of low potency of topical corticosteroids but even small doses of highly potent topical corticosteroids can also produce systemic side effects. Systemic side effects caused by TC include iatrogenic Cushing's syndrome, growth retardation in children, peripheral edema, glucose intolerance and hypertension. ${ }^{6}$

The present study was aimed to analyse the magnitude of adverse effects of topical corticosteroids abuse on the body in dermatology outpatient department of a tertiary care hospital. This study also helped to recognize the offending topical steroids in order of frequency.

\section{METHODS}

The present study was a retrospective observational study conducted in the Department of Pharmacology in collaboration with Department of Dermatology at S. N. Medical College and associated Hospital, Agra (U. P.) for duration of 6 months (Jan 2016- June 2016). The study was carried out after the approval of institutional ethics committee. A total of 1240 patients were screened for study.

Patients of age 15 to 50 years of either sex using topical corticosteroids without any dermatologist prescription were included in the study after obtaining their written informed consent.

Patients using topical corticosteroids after dermatologist prescription or in fixed dose combinations were excluded from study. Patients using two different molecules of topical corticosteroids for treatment of their skin disease were also excluded from the study.

Socio-demographic details of patients were collected. Details of drug misused were reported along with the adverse reactions. The study was carried out after the approval of institutional ethics committee.

All the data was collected in Microsoft excel sheet 2013 and analysed in percentage, mean and standard deviation.

\section{RESULTS}

A total of 1240 patients were screened over a period of 6 months for the present study. Patient visiting the Dermatology outpatient department for their skin problems along with a history of misuse of topical corticosteroids were first identified as a case of topical corticosteroid misuse. A total of 80 patients were included in the present study. Detailed history about indication for misuse, source of drug advice, type of drug use, pattern of drug use was taken from each patient. It was followed by a full clinical examination.

Patients included into study ranged from 15 to 50 years age group. Mean age of patients with topical corticosteroids misuse was $24.08 \pm 7.931$ years. Subgroup analysis suggested that mostly patients belong to age group $15-20$ years (43.8\%) followed by $28.8 \%$ in $21-25$ age group, $13.8 \%$ in $36-40$ age group, $10 \%$ in $26-30$ age group, $2.55 \%$ in $31-35$ age group and $1.3 \%$ in $45-50$ age group. No case was reported in age group 41-45 years (Table 1).

Mostly patients who presented with topical corticosteroid misuse were females (76\%). Population under study showed a gender distribution of male: female $=1: 3$ (Table 1). Most patients misused betamethasone valerate $(72.5 \%)$ followed by mometasone furoate (15\%), clobetasol propionate $(10 \%)$ and betamethasone dipropionate $(2.5 \%)$ (Figure 1). 
Table 1: Findings of reported patients.

\begin{tabular}{|ll|}
\hline Characteristic & Percentage (\%) \\
\hline Age distribution & \\
\hline $15-20$ & 43.8 \\
\hline $21-25$ & 28.8 \\
\hline $26-30$ & 10.0 \\
\hline $31-35$ & 2.50 \\
\hline $36-40$ & 13.8 \\
\hline $41-45$ & 00 \\
\hline $46-50$ & 1.30 \\
\hline Gender & \\
\hline Male & 24 \\
\hline Female & 76 \\
\hline Site of application & \\
\hline Face & 94 \\
\hline Whole body & 6 \\
\hline
\end{tabular}

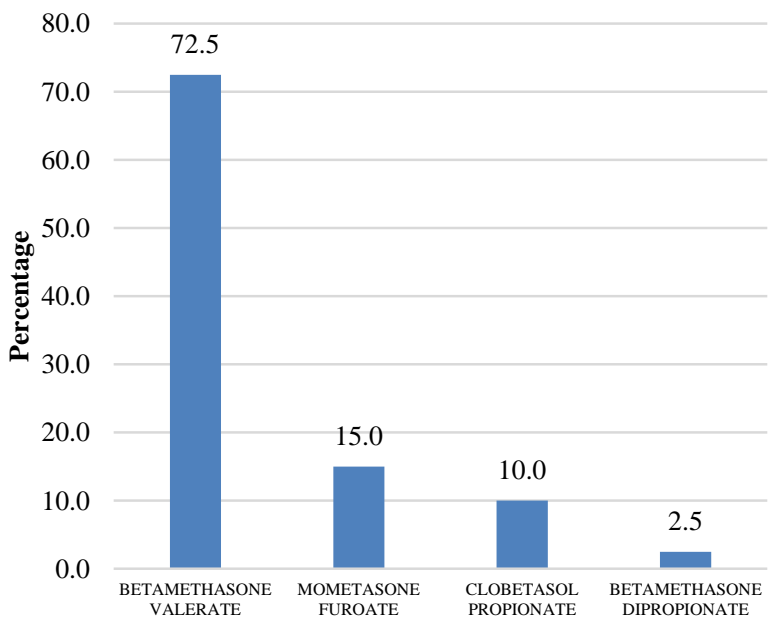

Figure 1: Topical corticosteroid drug misuse in the present study.

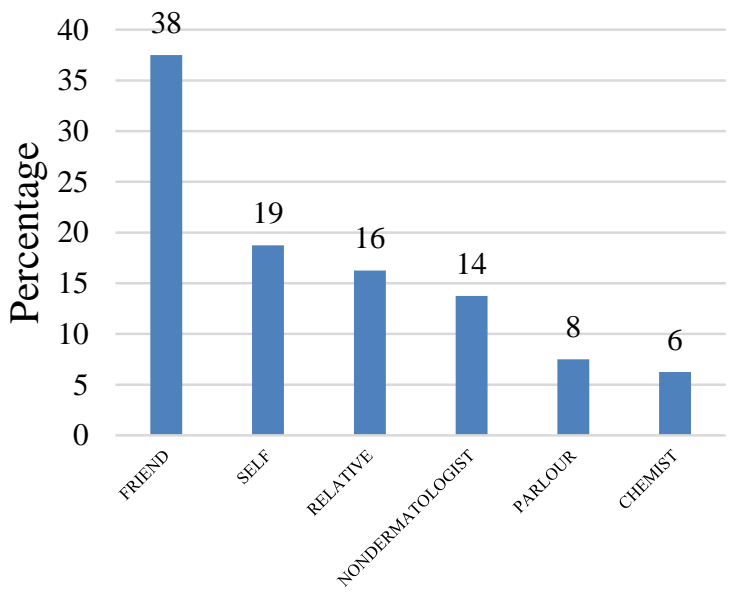

Figure 2: Source of advice to use topical corticosteroids.

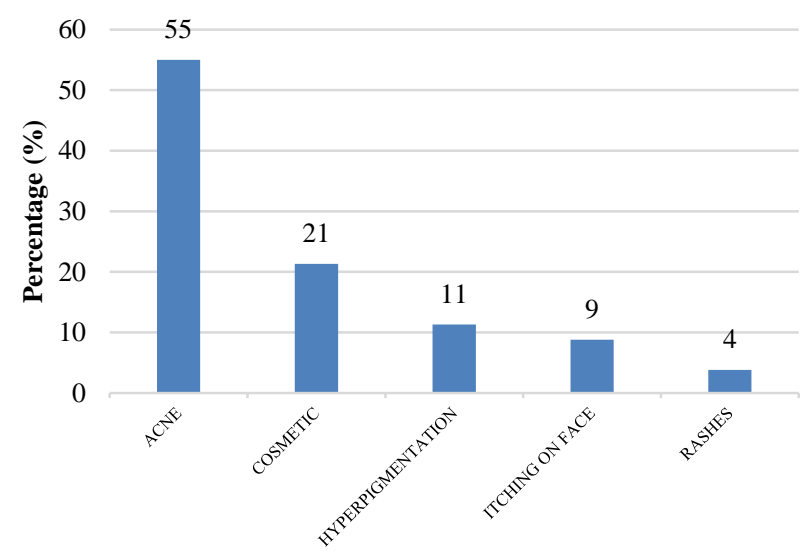

Figure 3: Purpose of misuse of topical corticosteroids.

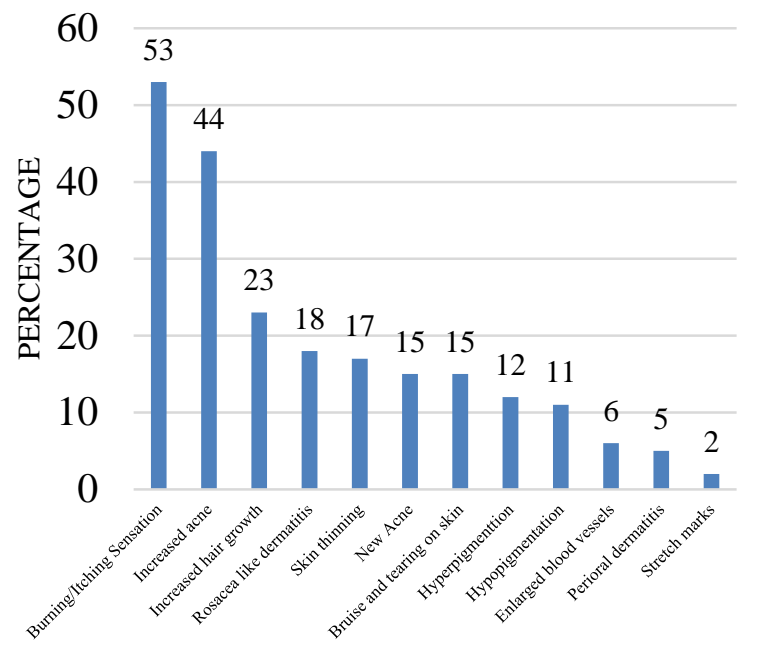

Figure 4: Adverse effects reported after misuse of topical corticosteroids.

Topical corticosteroids were most commonly advised to patients by their friends (38\%). Self-medication was seen in $19 \%$ patients whereas relatives and non-dermatologist doctors had suggested the drugs in $16 \%$ and $14 \%$ respectively (Figure 2). Misuse of topical corticosteroids was mainly done on the face $(94 \%)$ (Table 1). Patients misused topical corticosteroids mainly for acne in 55\% cases followed by cosmetic purposes (21\%), hyperpigmentation of skin $(11 \%)$, itch sensation on face $(9 \%)$ and rashes $(4 \%)$ (Figure 3$)$.

The most common morphological varieties of adverse drug reactions were burning and itching sensation (53\%) followed by increase severity of acne (44\%). Other reported adverse effects were increased hair growth $(23 \%)$, rosacea like dermatitis $(18 \%)$, skin thinning $(17 \%)$, new emergence of acne $(15 \%)$, bruise and tearing on the skin surface (15\%), hyperpigmentation (12\%), hypopigmentation $(11 \%)$, enlarged prominent blood vessels on the skin (6\%), perioral dermatitis (5\%) and stretch marks (2\%) (Figure 4). 


\section{DISCUSSION}

Problem of topical corticosteroid misuse is highly prevalent in Africa, Iraq and China. In India, the problem is even more complex, wherein anyone can easily get access to topical corticosteroids from chemist without a prescription by dermatologists. The problem is further complicated by the lack of awareness in general population about topical corticosteroids misuse.

A total of 80 patients of age group 15-50 years of either sex were enrolled in the present study after taking written informed consent. Mean age of patient in our study (24 years) was similar to study done by Sinha et al. ${ }^{7}$

Age wise distribution of the patients in the present study suggested that mostly patients belong to age group of 1520 year $(43.80 \%)$ followed by $21-25$ year $(28.70 \%)$. Our study is favoured by a study conducted in Iraq which suggest that most topical steroids abusers belong to 10-19 years age group. ${ }^{8}$ But this result is not favoured by studies conducted by Bhat et al, Saraswat et al and Sinha et al which shows that majority of population that misuse topical corticosteroids belong to 21-30 year age group. ${ }^{7,9,10}$ The difference of our study result from their studies can be due to lack of awareness in general population in our geographical area and fondness of young population for fair and acne free skin which drive them to seek advice from unauthorized sources and start misusing topical corticosteroids indiscriminately without proper guidance.

In this study, mostly patients who presented with topical corticosteroid misuse were female $(76 \%)$ which is similar to findings of all previous studies conducted in this field. This result is supported by the fact that females are more cosmetic concern and follows the directions of any adviser to attain fair and blemish free skin.

This study includes patients who came to dermatology department with a history of misuse of single type of topical corticosteroids and did not use any other drug for same disease. Mostly patients misused betamethasone valerate $(72.5 \%)$. This result is supported by the studies of Rathi et al and Nagesh et al. ${ }^{11,12}$ The reason for increased use of Betamethasone Valerate is due to easily availability and cheaper price of drug and household popularity of the brand name Betnovate.

Topical corticosteroids had been advised to patients by friends $(37 \%)$, by themselves $(18.8 \%)$, relatives $(16.3 \%)$, non-dermatologist doctor (13.8\%), parlour (7.5\%) and by chemists $(6.3 \%)$. Similar findings were seen in studies conducted by Saraswat et al, Rathi et al and Sinha et al where suggestion by friends come out to be a major factor to buy topical corticosteroid in the community. ${ }^{7,10,11}$ On the other hand, studies conducted by Dey et al shows that mostly patients were using topical corticosteroids on advice of pharmacists or paramedical personnel. ${ }^{13}$
Misuse of topical corticosteroids by patients is higher on face $(94 \%)$ as compare to application on whole parts of body $(6 \%)$. This finding is favoured by Nagesh et al, Bhat et al and Saraswat et al. ${ }^{9,10,12}$ This pattern of use is due to the misconception of increase in the fairness and as a treatment of acne by using topical corticosteroids on face.

This study revealed that topical corticosteroids was misused by patients mainly for acne $(55 \%)$ followed by cosmetic purposes $(21 \%)$, dark pigmentation of skin $(11 \%)$, itching on face $(9 \%)$ and rashes $(4 \%)$. Most common cause for misuse of topical corticosteroids is acne in this study which is similar to the finding of study conducted by Nagesh. ${ }^{12}$ Studies conducted by Sinha et al, Saraswat et al, Jha et al and Dey et al observed that desire of fairness or cosmetic purposes as most common cause of misuse of topical corticosteroids which is second most common indication of misuse in present study. ${ }^{7,10,13,14}$

The most common morphological varieties of adverse drug reactions were burning and itching sensation (53\%) followed by increase severity of acne (44\%). Our finding is similar to studies conducted by Rathi et al. ${ }^{11}$ Few studies like Dey et al, Jha et al and Saraswat et al reported steroid induced acne as most common adverse effect which is the second most common finding in this study. ${ }^{10,13,14}$

The present study highlights a serious social issue of selfmedication with topical steroids for beautification. The incidence of self-medication is mostly seen in the young adult population group. The alarming use of the steroids without proper guidance and suitable indication is associated with undesirable side effects.

The present study is also associated with limitation. Drug data generated from this study may not be truly reflective of the pattern of drug usage in the other tertiary care centre catering to patients with higher education and awareness. In this study the side effects of only pure topical corticosteroids are analysed. Hence side effects caused by topical corticosteroids available in fixed dose combinations are not taken into account. Paediatric and geriatric population was not included in this study, hence effect of topical corticosteroids misuse in this population cannot be elucidated. The present study reported cutaneous side effects of steroid misuse in the Dermatology OPD. No systemic reactions were reported in these patients.

Despite all these limitations, this study provides data confirming the extensive and uncontrolled use of topical corticosteroids in the study setting.

\section{CONCLUSION}

The problem of TC misuse is worsened in India because of improper advertisement by manufacturers, easy availability of steroids without prescription, improper prescription by non-dermatologists and lack of proper 
knowledge that has resulted in misuse of topical corticosteroid medications on a large scale. Free availability of all topical corticosteroids without a prescription has allowed many of the topical corticosteroids brands to become household names.

As indicated by the data in our study, this problem is already significant and urgent steps must be taken to control this problem. Collaboration of different sectors in the community is required to overcome this problem. We need to work at least on three pillars to eliminate this problem from society. First, increase in the awareness of general population by educating them through media programs. Second, educating medical, paramedical personnel and pharmacists by arranging continuing medical education programs. Lastly, enforcement of the existing legislation that potent topical corticosteroids should not be sold over-the-counter and without the prescription of a qualified doctor.

\section{ACKNOWLEDGEMENTS}

We thank the Department of Pharmacology, Department of Dermatology, Leprology and Venereology of S.N. Medical College, Agra and the participants of the study, for their support in completing this study.

Funding: No funding sources

Conflict of interest: None declared

Ethical approval: The study was approved by the Institutional Ethics Committee

\section{REFERENCES}

1. Rathi SK, D'Souza P. Rational and ethical use of topical corticosteroids based on safety and efficacy. Indian J Dermatol. 2012;57(4):251.

2. Pande S. Steroid containing fixed drug combinations banned by government of India: A big step towards dermatologic drug safety. Indian J Drugs Dermatol. 2016;2:1-2.

3. Nabar K. News of activity report of IADVL's taskforce against topical steroid abuse: Tireless efforts bringing fruits!!. Indian J Drugs Dermatol. 2015;1(1):56.

4. Verma SB, Vasani R. Male genital dermatophytosisclinical features and the effects of the misuse of topical steroids and steroid combinations-an alarming problem in India. Mycoses. 2016;59(10):606-14.

5. Coondoo A, Phiske M, Verma S, Lahiri K. Sideeffects of topical steroids: A long overdue revisit.Indian Dermatol Online J. 2014;5(4):416.

6. Dhar S, Seth J, Parikh D. Systemic side-effects of topical corticosteroids. Indian J Dermatol. 2014;59(5):460.

7. Sinha A, Kar S, Yadav N, Madke B. Prevalence of topical steroid misuse among rural masses. Indian $\mathbf{J}$ Dermatol. 2016;61(1):119.

8. Al Dhalimi MA, Al Jawahiry N. Misuse of topical corticosteroids: a clinical study in an Iraqi hospital. EMHJ - Eastern Mediterranean Health J. 2006;12(6):847-52.

9. Bhat YJ, Manzoor S, Qayoom S. Steroid-induced rosacea: A clinical study of 200 patients. Indian J Dermatol. 2011;56:30-2.

10. Saraswat A, Lahiri K, Chatterjee M, Barua S, Coondoo A, Mittal A, et al. Topical corticosteroid abuse on the face: A prospective, multicenter study of dermatology outpatients. Indian J Dermatol Venereol Leprol. 2011;77(2):160.

11. Rathi SK, Kumrah L. Topical corticosteroid-induced rosacea-like dermatitis: A clinical study of 110 cases. Indian J Dermatol Venereol Leprol. 2011;77(1):42.

12. Nagesh TS, Akhilesh A. Topical steroid awareness and abuse: A prospective study among dermatology outpatients. Indian J Dermatol.2016;61(6):618.

13. Dey VK. Misuse of topical corticosteroids: A clinical study of adverse effects Indian Dermatol Online J. 2014;5(4):436-40.

14. Jha AK, Sinha R, Prasad S. Misuse of topical corticosteroids on the face: A cross-sectional study among dermatology outpatients. Indian Dermatol Online J. 2016;7(4):259.

Cite this article as: Saini B, Chahar Y, Goyal YK, Kumar M, Bandyopadhyay A. Topical corticosteroid misuse: observational study to evaluate pattern of abuse and adverse drug reactions. Int J Basic Clin Pharmacol 2019;8:2064-8. 